\title{
Celiac disease in the Red Sea state of Sudan
}

\author{
Ali KAgeep
}

\section{ABSTRACT}

Department of Pathology, Faculty of Medicine, Red Sea University, Port Sudan,

Sudan

Correspondence:

Dr. Ali Khidir Ageep

Email:aleykh@yahoo.com
Background and aim: Celiac disease is characterized by sensitivity to gluten that results in inflammation and atrophy of the small intestine mucosa. The aim of this research was to document the presence of celiac disease and to describe its clinical presentations in the tribes living in the Red Sea state of Sudan.

Methods: 172 patients suspected to have celiac disease, were examined at the Red Sea Medical Center laboratory, Port Sudan, Sudan, from August 2008 to September 2011. All clinical data was collected using questionnaires. Serum samples were obtained from all patients for serological detection of anti-gliadin (AG) and anti-tissue transglutamase (ATTG) antibodies ( $\operatorname{IgG}$ and $\operatorname{Ig} \mathrm{A}$ ) using the enzyme-linked immuno-sorbent assay (ELISA).

Results: 128 patients were found to have celiac disease. The commonest presenting symptom was chronic diarrhea (20.3\%) followed by weight loss (14\%). Males and females were nearly equally affected. All age groups were affected with a peak incidence between 5 to 10 years . Conclusions: Celiac disease occurs in the Red Sea state and may well be under-diagnosed. The combination of IgA AGA and IgA ATTG tests represent a good diagnostic method to confirm celiac disease in suspected cases. Special attention needs to be given to methods that encourage adherence to gluten-free diet in affected people in this region.

KEYWORDS: celiac disease, gluten, anti-tissue transglutamase, Port Sudan

\section{Introduction}

Celiac disease $(\mathrm{CD})$ is a hereditary intolerance to gluten, a protein found in wheat and to a lesser extent in barley, rye and oat. Its prevalence has been underestimated, but it is now considered one of the most common genetic disorders in the West with a prevalence of $1-2.67 \% .^{1-3}$ The clinical manifestations are a manifestation of malabsorption and include symptoms of diarrhea, steatorrhea and nutritional and vitamin deficiencies. Secondary immunologic illnesses, such as atopic dermatitis, dermatitis herpetiformis, alopecia and aphthous ulcers may be the primary presentation. ${ }^{4}$ The disease is diagnosed in about $10 \%$ of first degree relatives of an individual with celiac disease. ${ }^{5}$ Although hereditary factors play a significant role, genetic factors alone do not explain the development of the disease because the disease is concordant in only 60 to $70 \%$ of identical twins. ${ }^{6}$ All people with HLADQ2 and DQ8 alleles do not develop the disease and others without these alleles have been observed to develop celiac disease, thus indicating involvement of hitherto uncharacterized genes. Additional factors such as hormones and infectious agents may also be putative in triggering aberrant interactions between ingested gluten and the host's mucosal immune system, thereby establishing a chronic inflammatory reaction in the intestines of genetically predisposed individuals. ${ }^{6}$ The prevalence of clinically diagnosed disease is $0.05-0.27 \%$ in various studies. ${ }^{7}$ 
However, population studies from parts of Europe, India, South America, Australasia and the USA (based on serology and histopathology) indicate that the prevalence may be between 0.33 and $1.06 \%$ in children $5.66 \%$ in one study of Sahrawi children $)^{7}$ and $0.18-1.2 \%$ in adults. ${ }^{8}$ The earliest described patients of celiac disease in Sudan were reported by Suliman in $1978,{ }^{9}$ but no data concerning the prevalence of the disease in Sudan or its Red Sea state is available till date.

This is the first study which documents the presence of celiac disease among different tribes in Eastern Sudan. The primary aim of this research was to confirm the presence of celiac disease in the Red Sea state of Sudan. This data will help sensitize our local health staff towards celiac disease, thus encouraging delivery of appropriate clinical management and health care facilities to these patients. We have also attempted to discuss the varying clinical presentations of the disease in our study.

\section{Methods}

One hundred and seventy two patients suspected to have celiac disease were examined at the Red Sea Medical Center laboratory, Port Sudan, Sudan, from August 2008 to September 2011. As per the 2002 national census the region has a total population of 739,300, after adjusted growth rates. Five main tribes exist in this area. The population distribution of these tribes is as follow: 43\% Hadandwa, 28\% Benne Ammer, 5\% Rashayda, $19 \%$ Northern Sudan tribes and 5\% Western Sudan tribes.

All clinical and epidemiological data including age, sex, presenting complaints and the tribe characteristics were collected using questionnaires. Ethical clearance of this study was obtained from the regional Ethical Review Committee (ERC).

Serum samples were obtained from all patients for serological detection of anti-gliadin and anti-tissue transglutamase antibodies (IgG and $\operatorname{IgA}$ ) using a customized enzyme-linked immuno-sorbent assay (ELISA) (EUROIMMN Medizinische Labordiagnostika AG). The assays were carried out as per the manufacturer's instructions. Briefly, patient sera were first diluted 1:20 in sample buffer. A $100 \mu \mathrm{l}$ each of the calibrators, negative controls, positive controls and diluted samples were next transferred into the individual microplate wells and then incubated for 30 minutes. Subsequently the wells were emptied and washed three times using $300 \mu \mathrm{l}$ of working strength wash buffer for each well. Thereafter $100 \mu \mathrm{l}$ of enzyme conjugate (peroxidase-labelled anti-human IgG) was added to each well and incubated for another 30 minutes. Post incubation the same washing procedure was repeated, followed by addition of $100 \mu \mathrm{l}$ of chromogen/substrate solution to each well and 15 minutes of incubation in the dark. Finally $100 \mu$ of stop solution was added to each well in the same order and at the same speed as the substrate solution was introduced. Photometric measurement of color intensity was recorded by an ELISA reader at a wavelength of $450 \mathrm{~nm}$ within 30 minutes of adding the stop solution. The cut-off value of the test was $20 \mathrm{RU} / \mathrm{ml}$.

\section{Statistical analysis}

Data were analyzed by using the Statistical Package for Social Sciences (SPSS) version 16.0 and results were compiled as frequencies and percentages.

Table 1: Shows the clinical presentations of celiac disease in the different sex and age groups

\begin{tabular}{|c|c|c|c|c|c|c|c|c|c|}
\hline Presenting complain & Males & Females & $<5$ years & 5-10 years & 10-20years & 20-30years & 30-50years & 50-60years & Total (\%) \\
\hline Chronic diarrhea & 12 & 14 & 8 & 10 & 3 & 3 & 2 & 0 & $26(20.3)$ \\
\hline Weight loss & 10 & 8 & 7 & 10 & 1 & 0 & 0 & 0 & $18(14.0)$ \\
\hline Flatulence, abdominal distention & 7 & 6 & 6 & 7 & 0 & 0 & 0 & 0 & $13(10.1)$ \\
\hline Foul-smelling stools & 5 & 3 & 2 & 5 & 1 & 0 & 0 & 0 & $8(6.3)$ \\
\hline Stomach pain, gas, and bloating & 3 & 4 & 0 & 1 & 3 & 2 & 0 & 1 & $7(5.5)$ \\
\hline Stunted growth & 10 & 7 & 7 & 8 & 2 & 0 & 0 & 0 & $17(13.3)$ \\
\hline Bone or joint pain & 5 & 7 & 0 & 3 & 3 & 3 & 2 & 1 & $12(9.4)$ \\
\hline Anemia & 7 & 7 & 6 & 7 & 1 & 0 & 0 & 0 & $14(10.9)$ \\
\hline Skin manifestations & 5 & 3 & 0 & 2 & 0 & 1 & 3 & 2 & $8(6.3)$ \\
\hline Peripheral neuropathy & 1 & 2 & 0 & 0 & 2 & 1 & 0 & 0 & $3(2.3)$ \\
\hline Infertility & 0 & 2 & 0 & 0 & 0 & 2 & 0 & 0 & $2(1.6)$ \\
\hline Total $(\%)$ & $65(50.8)$ & $63(49.2)$ & $36(28.1)$ & $53(41.4)$ & $16(12.5)$ & $12(9.4)$ & $7(5.5)$ & $4(3.1)$ & $128(100)$ \\
\hline
\end{tabular}


Table 2: Frequency of Celiac disease in different (Red Sea State) tribes.

\begin{tabular}{lcc}
\hline Tribe & Number & Frequency (\%) \\
\hline Benne Amer & 81 & 63.3 \\
Hadandwa & 18 & 14.1 \\
Rashayda & 9 & 7.0 \\
Northern Sudan & 16 & 12.5 \\
Western Sudan & 4 & 3.1 \\
\hline Total & $\mathbf{1 2 8}$ & $\mathbf{1 0 0}$ \\
\hline
\end{tabular}

Diagnostic criteria for celiac disease in this study

A patient was considered positive for celiac disease when the titer of anti-TTG and AG antibodies was found to be more than 10 times of the cut-off values. ${ }^{10-11}$

\section{Results}

Out of the 172 patients investigated for celiac disease, only 128 patients were confirmed positive for celiac disease. The remaining forty four negative patients were excluded from further analysis. The titers of antibodies were higher in the anti-tissue transglutamase tests than the anti-gliadin tests. The commonest presenting symptom was chronic diarrhea (20.3\%) followed by weight loss (14\%) (Table 1). The third common presentation was noted to be stunted growth (13.3\%). Males and females were nearly equally affected $(\mathrm{M}: \mathrm{F}=1: 0.97)$. All age groups were affected with a peak incidence between 5 to 10 years (41.4\%). Table 2 illustrates that the overwhelming majority of celiac disease is among the Benne Amir tribe (63.3\%), followed by the Hadandwa tribe (14.1\%) and the Northern Sudan tribes $(12.5 \%)$.

\section{Discussion}

Until the 1990s the presence of celiac disease in Sudan was considered low. However, with the introduction of assays for anti-tissue transglutamase antibodies (ATTGA) and antigliadin antibodies (AGA) CD has been more readily detected and reported from Sudan. ${ }^{12}$ To our knowledge, this is the first study which documents the presence of CD in the Red Sea state of Sudan.

The clinical presentation of $\mathrm{CD}$ varies from silent disease to full-fledged severe intestinal and extra-intestinal manifestations. ${ }^{1,2,13}$ In this study, chronic diarrhea was the most common presenting symptom (20.3\%). In Iran, Lebanon, Iraq, Saudi Arabia and Kuwait, CD has been reported to be one of the most common causes of chronic diarrhea. ${ }^{14-16}$ This is almost similar to our findings. The second common symptom was weight loss (14\%). In Egypt 4.7\% of children presenting with diarrhea and weight loss had CD. ${ }^{17}$ The variation in the prevalence of clinical manifestations of CD across different studies, may be due to the low number of patients evaluated or a delay in their presentation. Stunted growth represents the third most common presenting complaint (13.3\%). The highest prevalence of stunted growth was reported from Jordan where $26 \%$ of children with CD had rickets. ${ }^{18}$ In Turkey $51 \%$ of patients had a height $<2.5$ standard deviations below the mean. ${ }^{18}$ About one third of children with CD in Western countries develop short stature. ${ }^{19}$ Anemia was noted in $10.9 \%$ of the patients, and it was mainly due to iron deficiency in most of the cases. Worldwide prevalence of $\mathrm{CD}$ among patients with iron deficiency anemia is $2.8-8.7 \%$ and may be as high as $15 \% .^{20,21}$ Folate and $\mathrm{B}_{12}$ deficiency may contribute to anemia in $\mathrm{CD}$, and surprisingly, anemia of chronic disease is relatively common. ${ }^{22}$ The diagnosis of $\mathrm{CD}$ was confirmed by serological detection of the AGA and ATTGA. Tissue transglutamase IgA sensitivity is $70 \%-100 \%,{ }^{23,24}$ and its specificity is $99 \% .{ }^{24}$ The sensitivity of IgAAGA is about $80 \%$, while that of IgG AGA is $90-100 \% .{ }^{25,26}$ Endoscopic intestinal biopsy was not available in the region. Only one case of villous atrophy was diagnosed by a visiting gastroenterologist. Duodenal biopsy remains the gold standard for celiac disease (CD) diagnosis. However, it has several pitfalls and requires an invasive procedure even in children. In the past few years a more prominent role for a definitive diagnosis based solely on serology has been proposed. The predictive value of high levels of anti-tissue transglutamase antibodies has also been reported in retrospective $\mathrm{CD}$ cohorts. Based on these studies, some authors have proposed to start a glutenfree diet (GFD) for patients with high ATTG antibody levels, without a duodenal biopsy. ${ }^{11}$ Thus high levels of the serological markers remain the test of choice for detection of $\mathrm{CD}$ in our study region.

We believe that the prevalence of CD in the Red Sea state may be underestimated due to lack of awareness and low suspicion of the disease. Unfortunately, some doctors, especially in the rural areas, still do not know when to suspect celiac disease. Many physicians still do not realize there is no "typical" celiac disease patient. Celiac disease can begin at any age, persists for life and can affect multiple organs. People with celiac disease can be thin, obese or have normal weight. In both children and adults the symptoms of celiac disease can be extremely variable or there may be no symptoms at all. Unfortunately owing to the heterogeneity in the clinical 
presentation and lack of a standard clinical profile in CD, some patients go undiagnosed for years together despite several consultations with different doctors.

In this study, the vast majority of celiac disease cases were noted to occur in the Benne Ammer tribe (63.3\%). This tribe represents $28 \%$ of the whole population. In our study, the CD patients in the Benne Ammer tribe exceeded this figure by $35.3 \%$ (i.e. 1.3 times more than the expected ratio). Genetic and environmental factors may play a role in the higher prevalence of $\mathrm{CD}$ in this tribe. $\mathrm{CD}$ is strongly associated with the human leukocyte antigen (HLA) DQ2 and DQ8 alleles. ${ }^{27}$ Additional factors such as hormones and infectious agents may also be involved in the disease pathophysiology. ${ }^{6}$ The staple diet in this area constitutes mainly of sorghum. Suliman reported sorghum as one of the main sources of gluten in Sudan. ${ }^{9}$ A combined effort on the part of heath care workers and researchers to increase health education and help elucidate the specific risk factors for $\mathrm{CD}$ in this region are highly recommended.

Currently the only treatment for celiac disease is a glutenfree diet. ${ }^{3}$ Dietary avoidance of gluten leads to symptom improvement in $70 \%$ of patients within 2 weeks. ${ }^{28}$ However, complete histological resolution of small bowel inflammation may take up to 2 years in some individuals. ${ }^{29}$ It can be challenge to avoid gluten in eastern Sudan. Poverty and ignorance are the major obstacles in such developing regions. As the pathophysiology of celiac disease gets clearer, new methods of treatment are being developed including orally active drugs. ${ }^{30}$

\section{Conclusions}

Celiac disease occurs in the Red State and may well be underdiagnosed. The combination of AGA IgG and ATTG IgA tests represents a good diagnostic method for diagnosis of suspected cases of celiac disease. Special attention needs to be given to methods that encourage adherence to gluten-free diet in affected people in this region. Large prospective studies are needed to assess the true incidence, the clinical course, the efficacy of treatment modalities employed, patient compliance, disease complications and response to treatment in eastern Sudan.

\section{References}

1. Rostom A, Murray JA, Kagnoff MF. American Gastroenterological Association (AGA) Institute technical review on the diagnosis and management of celiac disease. Gastroenterology. 2006;131:1981-2002.

2. Green PH, Cellier C. Celiac disease. $N$ Engl J Med. 2007;357:1731-43.

3. Fasano A, Berti I, Gerarduzzi T, Not T, Colletti RB, Drago S, et al. Prevalence of celiac disease in at-risk and not-at-risk groups in the United States: a large multicenter study. Arch Intern Med. 2003;163:286-92.

4. Fine JD. Immunobullous diseases. In: Sams WM Jr, Lynch PJ, editors. Principles and practice of dermatology. 2nd ed. New York: Churchill Livingstone; 1996. p. 461.

5. Logan RFA. Epidemiology of celiac disease. Celiac disease. Oxford: Blackwell Scientific; 1992.p. 192-4.

6. Fasano A. Where have all the American celiacs gone? Acta Pediatr Suppl. 1996;412:20-4.

7. Catassi C, Rätsch I, Gandolfi L, Pratesi R, Fabiani E, El Asmar R, et al. Why is coeliac disease endemic in the people of the Sahara? Lancet. 1999:354:647-8.

8. Van Heel DA, West J. Recent advances in coeliac disease. Gut. 2006; 55:1037-46.

9. Suliman GI. Coeliac disease in Sudanese children. Gut. 1978;19:121-5.

10. Barker CC, Mitton C, Jevon G, Mock T. Can tissue transglutaminase antibody titers replace small-bowel biopsy to diagnose celiac disease in select pediatric populations? Pediatrics. 2005;115:1341-6.

11. Vivas S, Ruiz de Morales JG, Riestra S, Arias L, Fuentes D, Alvarez N, et al. Duodenal biopsy may be avoided when high transglutaminase antibody titers are present. World Journal Gasetroentrol. 2009;15:4775-80.

12. Mohammed IM, Karrar ZE, El-Safi SH. Celiac disease in Sudanese children with clinical features suggestive of the disease. East Mediterr Health J. 2006;12:582-9.

13. Alaedini A, Green PH. Narrative review: celiac disease: understanding a complex autoimmune disorder. Ann Intern Med. 2005;142:289-98.

14. Shahbazkhani B, Mohamadnejad M, Malekzadeh R, Akbari MR, Esfahani MM, Nasseri-Moghaddam S, et al. Coeliac disease is the most common cause of chronic diarrhoea in Iran. Eur $J$ Gastroenterol Hepatol. 2004;16:665-8.

15. Zoabi B, Naja Z, Rajab M. Chronic diarrhea in children at MGH over a five years period. Revue Medical Libanaise. 2003;15:145-9.

16. Al-Bayatti SM. Etiology of chronic diarrhea. Saudi Med J. 2002;23:675-9.

17. Abu-Zekry M, Kryszak D, Diab M, Catassi C, Fasano A. Prevalence of celiac disease in Egyptian children disputes the east-west agriculture-dependent spread of the disease. J Pediatr Gastroenterol Nutr. 2008;47:136-40.

18. Doganci T, Bozkurt S. Celiac disease with various presentations. Pediatr Int. 2004;46:693-6.

19. D’Amico MA, Holmes J, Stavropoulos SN, Frederick M, Levy J, DeFelice AR, et al. Presentation of pediatric celiac disease in the United States: prominent effect of breastfeeding. Clin Pediatr (Phila). 2005;44:249-58.

20. Annibale B, Capurso G, Chistolini A, D’Ambra G, DiGiulio E, Monarca B, et al. Gastrointestinal causes of refractory iron 
deficiency anemia in patients without gastrointestinal symptoms. Am J Med. 2001;111:439-45.

21. Grisolano SW, Oxentenko AS, Murray JA, Burgart LJ, Dierkhising RA, Alexander JA. The usefulness of routine small bowel biopsies in evaluation of iron deficiency anemia. J Clin Gastroenterol. 2004;38:756-60.

22. Harper JW, Holleran SF, Ramakrishnan R, Bhagat G, Green PH. Anemia in celiac disease is multifactorial in etiology. Am J Hematol. 2007; 82:996-1000.

23. Tatar G, Elsurer R, Simsek H, Balaban YH, Hascelik G, Ozcebe OI, et al. Screening of tissue transglutaminase antibody in healthy blood donors for celiac disease screening in the Turkish population. Dig Dis Sci. 2004;49:1479-84.

24. Akbari MR, Mohammadkhani A, Fakheri H, Javad Zahedi M, Shahbazkhani B, Nouraie M, et al. Screening of the adult population in Iran for coeliac disease: comparison of the tissuetransglutaminase antibody and anti-endomysial antibody tests. Eur J Gastroenterol Hepatol. 2006;18:1181-6.

25. Mankaï A, Landolsi H, Chahed A, Gueddah L, Limem M, Ben
Abdessalem M, et al. Celiac disease in Tunisia: serological screening in healthy blood donors. Pathol Biol (Paris). 2006;54:10-3.

26. Fayed SB, Aref MI, Fathy HM, Abd El Dayem SM, Emara NA, Maklof A, et al. Prevalence of celiac disease, Helicobacter pylori and gastroesophageal reflux in patients with refractory iron deficiency anemia. J Trop Pediatr. 2008;54:43-53.

27. Kim CY, Quarsten H, Bergseng E, Khosla C, Sollid LM. Structural basis for HLA-DQ2-mediated presentation of gluten epitopes in celiac disease. Proc Natl Acad Sci U S A. 2004;101:4175-9.

28. Pink IJ, Creamer B. Response to a gluten-free diet of patients with coeliac syndrome. Lancet. 1967;1:300-4.

29. Grefte JM, Bouman JG, Grond J, Jansen W, Kleibeuker JH. Slow and incomplete histological and functional recovery in adult gluten sensitive enteropathy. J Clin Pathol. 1988;41:886-91.

30. Shan L, Molberg Ø, Parrot I, Hausch F, Filiz F, Gray GM, et al. Structural basis for gluten intolerance in celiac sprue. Science. 2002;297:2275-9. 